\title{
O DESAFIO DA UTILIZAÇÃO DE ESTRATÉGIAS DE MARKETING PARA EMPRESAS DE PEQUENO PORTE
}

\author{
Gislaine Santos ${ }^{1}$, Agessander Manoel $^{2}$ \\ ${ }^{1}$ Universidade do Oeste Paulista - UNOESTE, Gestão Comercial, Presidente Prudente, SP. ${ }^{2}$ Universidade do Oeste \\ Paulista - UNOESTE, curso de Administração, Presidente Prudente, SP. E-mail: gislaine.farias@outlook.com; \\ agessandermanoel@hotmail.com
}

\section{RESUMO}

As empresas de pequeno porte têm assumido um papel de destaque na economia brasileira e responderem em média por aproximadamente $99 \%$ dos empreendimentos formais, $52 \%$ dos empregos formais e $40 \%$ da massa salarial. Este artigo discute o desafio da utilização de estratégias de marketing para empresas de pequeno porte, para que satisfaçam as necessidades de desejos dos clientes alvo e entreguem valor, respeitando os limites de seu crescimento e lucratividade e tem como objetivo oferecer um debate com pesquisadores que tratam da aplicabilidade de estratégias de marketing independente do porte das empresas.

Palavras-chave: Pequenas Empresas. Marketing. Estratégias. Empreendedorismo.

\section{THE CHALLENGE OF THE USE OF MARKETING STRATEGIES FOR SMALL BUSINESS}

\begin{abstract}
Small businesses have assumed a prominent role in the Brazilian economy and account on average for approximately $99 \%$ of formal enterprises, $52 \%$ of formal jobs and $40 \%$ of wages. This paper discusses the challenge of using marketing strategies for small businesses so that they meet the target customer's needs and deliver value while respecting the limits of their growth and profitability and aims to offer a debate with researchers who treat of the applicability of marketing strategies independent of the size of the companies.
\end{abstract}

Keywords: Small Business. Marketing. Strategies. Entrepreneurship.

\section{INTRODUÇÃO}

As empresas têm sido pressionadas a desenvolver e empregar estratégias mais arrojadas e cada vez mais focadas no cliente, estabelecendo um ritmo competitivo capaz de garantir a sua própria sobrevivência e expansão. $O$ marketing é uma ferramenta extremamente importante para a gestão de empresas e é decisivo para o sucesso, pois orienta a empresa a oferecer ao mercado produtos e serviço que atendam as necessidades e desejos do público alvo, fazendo com que o processo de troca se torne a melhor opção para o cliente.

O sucesso de uma empresa passou a depender da agilidade nas decisões, da eficácia nos resultados e dos serviços ao consumidor. Kotler e Keller (2006) explicam que funções básicas, como finanças, operações, contabilidade e outras também são importantes, mas perdem o sentido se o marketing não provocar uma demanda adequada para os produtos e serviços ofertados, garantindo a lucratividade desejada e necessária.

Halloran (1994) compara a responsabilidade do gestor comercial de uma pequena organização com a de um alto executivo de uma grande organização, explicando que o domínio dos diversos campos de conhecimento e a correta aplicação das ferramentas administrativas e de 
marketing ao negocio é fundamental para o desenvolvimento de forma competitiva e sustentável, independente do porte da organização.

Segundo Almeida (1995), o planejamento estratégico é uma técnica administrativa que procura ordenar as ideias, de forma que se possa criar uma visão estratégica do caminho que a empresa deve seguir, pois a criação de valor tanto nas organizações recém-criadas quanto nas já estabelecidas é uma tarefa complexa e desafiadora. A liderança estratégica cria condições favoráveis para a maximização do retorno sobre o investimento.

Magalhães (2006) é claro ao definir mercado - alvo como um grupo de consumidores a quem a empresa decide dirigir seus produtos, serviços ou ideias, com uma estratégia destinada a satisfazer suas necessidades e preferências específicas. As grandes empresas investem em marketing e isto permite que tenham maior participação no mercado, lucratividade, reconhecimento de marca, entre outros benefícios. A proposta de marketing funciona de igual modo nas empresas de pequeno porte, dentro de sua realidade e como um diferencial competitivo no mercado, permitindo que as empresas com esta visão cresçam mais rapidamente que as demais concorrentes diretas e ganhem liderança competitiva evoluindo para patamares maiores.

A discussão deste tema se justifica por ser relevante para as empresas de pequeno porte e ter como objetivo oferecer um debate com pesquisadores que tratam da aplicabilidade de estratégias de marketing independente do porte das empresas.

\section{METODOLOGIA}

O método utilizado nesta discussão de estratégias de marketing para empresas de pequeno porte é a pesquisa bibliografia, pois segundo Lakatos e Marconi (1991) esta técnica apresenta as principais conclusões que outros pesquisadores chegaram ao estudar um determinado problema. As contribuições dos pesquisadores e da entidade que apoia a micro e pequenas empresas usadas como referência bibliográfica, promovem a discussão do tema proposto com bases científicas, melhorando a compreensão do objeto de estudo (as empresas de pequeno porte) e o objetivo proposto (debater a importância das estratégias de marketing para as empresas de pequeno porte), oferecendo uma visão científica da realidade do tema proposto ao observar os vários aspectos discutidos.

\section{RESULTADOS}

De acordo com o Serviço Brasileiro de Apoio às Micro e Pequenas Empresas - SEBRAE (2013), as empresas de menor porte podem ser classificadas de acordo com a Lei Geral das Microempresas e Empresas de Pequeno Porte que foi instituída em 2006, tanto pelo faturamento bruto anual ou pelo número de empregados. Ela entende que microempreendedor individual são aqueles que faturam até $\mathrm{R} \$ 60.000,00$ por ano, as microempresas são as que faturam até $\mathrm{R} \$ 360.000,00$ por ano e as empresa de pequeno porte são as que faturam de $\mathrm{R} \$ 360.000,01$ à $\mathrm{R} \$ 3.600 .000,00$ ao ano. Quanto ao número de empregados, o quadro abaixo traz um melhor entendimento sobre esta classificação:

\begin{tabular}{|l|l|l|}
\hline PORTE & COMERCIO/SERVIÇOS & INDÚSTRIA \\
\hline Microempresa (ME) & Até 9 empregados & Até 19 empregados \\
\hline $\begin{array}{l}\text { Empresa de Pequeno } \\
\text { Porte(EPP) }\end{array}$ & De 10 a 49 empregados & De 20 a 99 empregados \\
\hline Empresa de médio porte & De 50 a 99 empregados & De 100 a 499 empregados \\
\hline Grandes empresas & 100 ou mais empregados & 500 ou mais empregados \\
\hline
\end{tabular}


Segundo o SEBRAE (2014), as MPE's respondem, em média, por aproximadamente $99 \%$ dos empreendimentos formais no Brasil, $52 \%$ dos empregos formais e $40 \%$ da massa salarial. Assim, a micro, pequenas e médias empresas têm assumido um papel de destaque na economia brasileira e isso se deve tanto pela capacidade de gerar empregos e renda quanto pelo aumento do número de estabelecimentos nos últimos anos. O grande desafio dos administradores que atuam neste segmento é o de buscar a sensibilidade no mercado para sua empresa, a inovação e a tecnologia do produto e sua adequação a novos modelos de gestão.

O SEBRAE (2014) aponta ainda que o problema não é a falta de recursos destas empresas, mas o baixo conhecimento necessário para fazer um bom uso do mesmo, decorrente de uma baixa utilização de planejamento e ferramentas administrativas e comerciais que poderiam auxiliar na tomada de decisão.

Outro estudo do SEBRAE (2014) mostra os seguintes dados: $46 \%$ dos pesquisados não sabem o número de clientes que podem ter ou seus hábitos de consumo, 39\% não sabem qual o capital de giro necessário para abrir o negócio, 38\% não sabem o número de concorrentes que terão, 37\% não sabem a melhor localização para o seu negócio, 33\% não tem informações sobre fornecedores, 32\% não conhecem os aspectos legais do negócio, 31\% não sabem o investimento necessário para o negócio e $18 \%$ não levantaram a qualificação necessária da mão de obra no planejamento prévio. São dados estarrecedores do perfil dos empresários de micro e pequenas empresas, contudo estes dados não devem desestimular o empreendedorismo, mas servir de aprendizado para uma melhor chance de sobrevivência, como proposto neste trabalho.

\section{DISCUSSÃO}

No universo das pequenas empresas o planejamento estratégico de marketing como processo contínuo de integração da empresa com o ambiente, visando estabelecer objetivos e estratégias, é pouco utilizado levando-as a ineficiência e fragilidade. Segundo Sobanski (1995), o crescente dinamismo e a competitividade encontrados no ambiente empresarial vêm gerando novas formas de organização e interação entre os diversos agentes econ6omicos e sociais, ao mesmo tempo em que induzem à criação e consolidação de instrumentos e estilos de gestão adaptados às novas necessidades.

Kotler e Keller (2006) afirmam que é importante que as empresas ao desenvolverem a uma estratégia de marketing estejam sempre aprimorando e combinando disciplina e flexibilidade, sabendo o que, quando e para quem fazer. A elaboração da estratégia de marketing é um processo, e sua primeira etapa é a determinação do mercado alvo, que consiste em saber qual tipo de publico a empresa quer atingir, uma vez que não se pode atender a todos os clientes do mercado.

Ao determinar as estratégias de marketing, é importante saber como satisfazer o que o cliente espera, suprindo suas necessidades e seus desejos. Para isso é necessário que se concilie a entrega de valor sem afetar a lucratividade. Desenvolver uma estratégia que envolva essa característica não é fácil, pois a economia e as variedades de opções encontradas no mercado são grandes obstáculos.

Almeida (1995) diz que as pequenas empresas são eficientes no seu dia-a-dia, mas ineficazes nas decisões estratégicas. Existem empresas que mantém uma visão tradicional e não procuram oferecer produtos e serviços diferenciados, com valor agregado, porque acreditam que a necessidade por seus produtos garantirá o processo de troca. Entretanto, os mercados são competitivos e a variedade e opções de ofertas, determinam critérios para aquisição de bem ou serviço, obrigando as empresas a ofertarem valor em seus produtos. Por isto as empresas devem desde a criação até a venda focar na entrega de valor ao cliente 
Kotler e Keller (2006) deixam claro que processo de marketing começa antes da existência de um produto, continua enquanto ele é desenvolvido e permanece depois que se torna disponível criando uma cadeia de valor. Segundo eles a cadeia de valor é uma ferramenta para identificar as maneiras pelas quais se pode criar mais valor para o cliente e nesse modelo, toda empresa trabalha em uma atividade única: projetar, produzir, comercializar, entregar, e sustentar o produto com valor percebido pelo cliente.

Segundo Vasconcelos Filho (1985), administrar estrategicamente é permear, em todos os níveis da organização, a consciência de que a empresa deve viver em função de um pensamento maior, estratégico, e não em função de negócios de oportunidade. Kotler e Keller (2006) discutem que as empresas que definem objetivos de criação de valor para elaborar um planejamento estratégico, devem entender a relação entre três espaços. O primeiro é o espaço cognitivo do cliente, que reflete as necessidades existentes e latentes, o segundo espaço é o da competência da empresa, que pode ser definido em termos de amplitude e profundidade, e o terceiro espaço é o de recurso do colaborador, que são escolhidos e definidos pelas suas habilidades.

Assim o planejamento estratégico orientado para o mercado é desenvolvido nos níveis corporativo, de unidade de negócios e de produto, sendo que os objetivos desenvolvidos no nível corporativo devem se desdobrar para os níveis inferiores, onde os planos são preparados para guiar as atividades da empresa.

Dentro deste planejamento estratégico, existe a elaboração de um plano de marketing, que é o instrumento central para direcionar os esforços de marketing, tanto no nível estratégico como no tático. Estrategicamente ele estabelece os mercados alvo e a proposta de valor que será oferecida, com base em uma análise com as melhores oportunidades de mercado. O nível tático trata das táticas de marketing, incluindo características do produto, promoção, comercialização, determinação do preço, canais de vendas e serviços. Toda essa exigência competitiva e os clientes cada vez mais exigentes levam as organizações a pensarem na sua estrutura para se adequar ao mercado. Com isso as pequenas empresas precisam se adaptar a estas exigências para poderem crescer cada vez mais.

\section{CONCLUSÃO}

Com os resultados apresentados pela SEBRAE (2014) o problema das micro e pequenas empresas não é a falta de recursos e sim o baixo conhecimento necessário para fazer um bom uso do mesmo, decorrente de baixa utilização de planejamento e ferramentas administrativas e comerciais.

O planejamento estratégico de marketing deve ser visto pelas pequenas empresas como uma ferramenta de inúmeros benefícios para a competitividade e que pode auxilia-la na identificação e operacionalização de estratégias de ganho de mercado. Conclui-se que ao desenvolver uma estratégia de marketing dentro da organização, a postura pró ativa de gestão possibilitará a obtenção de melhores chances de sobrevivência num ambiente que se torna mais competitivo a cada dia.

\section{REFERÊNCIAS BIBLIOGRÁFICAS}

ALMEIDA, M. I. R. Desenvolvimento de um modelo de Planejamento Estratégico para grupos de pequenas empresas. 1995.Tese Doutorado. Faculdade de Economia, Administração e Contabilidade, Universidade de São Paulo, São Paulo, SP, Brasil.

HALLORAN, J. W. Por que os empreendedores falham. São Paulo: Makron Books, 1994. 
KOTLER,P. ; KELLER, K.L. Administração de Marketing. 12a Edição. São Paulo: Editora Pearson Prentice Hall, 2006.

LAKATOS, M.; MARCONI, M. A. Metodologia Científica. 2a․ ed. São Paulo: Atlas, 1991.

MAGALHÃES, M.F. Explicando marketing, simplesmente. Rio de Janeiro: Qualitymark, 2006.

SEBRAE. Anuário do Trabalho na Micro e Pequena Empresa. Disponível em: <www.sebrae.com.br/Sebrae/Portal\%20Sebrae/Anexos/Anuario\%20do\%20Trabalho\%20Na\%20Mi cro\%20e\%20Pequena\%20Empresa_2013.pdf>. Acesso em 02 mar 2017.

SEBRAE. Participação das Micro e Pequenas Empresas na Economia Brasileira. Disponível em: <https://www.sebrae.com.br/Sebrae/Portal\%20Sebrae/

Estudos\%20e\%20Pesquisas/Participacao\%20das\%20micro\%20e\%20pequenas\%20empresas.pdf>.

Acesso em 02 mar 2017.

SOBANSKI, A.R. Implementação de estratégias: estudo exploratório de alguns fatores críticos.

Dissertação de mestrado. São Paulo. FEA-USP, 1995.

VASCONCELOS FILHO, P. Planejamento estratégico para a retomada do desenvolvimento. Rio de Janeiro, LTC - Livros Técnicos e Científicos Editora S.A., 1995. 